\title{
NOTAS E INFORMAÇÕES
}

\section{EXPANDINDO AS FRONTEIRAS DA EDUCAÇÃO EM ENFERMAGEM GLOBALMENTE*}

FOCO: PESQUISA EM EDUCAÇÃO EM ENFERMAGEM

\section{PLANOS E ESTRATÉGIAS PARA A PESQUISA EM EDUCAÇÃO EM ENFERMAGEM: EM DIREÇÃO AO TERCEIRO MILÊNIO}

Renzo Zanotti **

A Educação terá um papel essencial na construção do futuro da enfermagem, sendo primordial na preparação de profissionais como enfermeiras clínicas, administradoras, educadoras e pesquisadoras em todo o mundo, assim como no aperfeiçoamento da qualidade dos cuidados de enfermagem. A partir das exigências deste mundo em constantes mudanças, a enfermagem deve assumir uma perspectiva cada vez mais internacional. Desse modo, enfermeiras educadoras devem continuamente examinar e desenvolver o conteúdo já existente e introduzir novas metas, conteúdos e métodos de ensino que alcancem as necessidades das pessoas a quem servem.

* Conferência Internacional de Bolzano - Itália - 1993 - Síntese de suas principais discussões - traduzido por Carla Aparecida Arena Ventura ** Diretor - International Institute of Nursing Research of Padua 
A pesquisa se constitui em um caminho importante para o desenvolvimento de novos programas e instrumentos. A Conferência Internacional: Expandindo as fronteiras da educação em enfermagem globalmente abordou a necessidade de um aumento de pesquisas sobre educação em enfermagem. Através deste documento, o Comitê Científico da Conferência oferece urna contribuição para o tópico, emergido de sugestões de todos os participantes da Conferência e de muitos encontros entre os membros do Comitê. Esse documento é apresentado como um plano para o futuro. As questões chaves são identificadas, com particular atenção ao preenchimento das grandes lacunas no conhecimento sobre pesquisa e na determinação de condições para colaborações globais futuras.

Nós esperamos que esse Documento siNa corno base para discussão em muitas instituições educacionais e de pesquisas e como estímulo para a cooperação e o desenvolvimento de projetos de pesquisa sobre educação em enfermagem.

Esse documento relata elementos referentes a:

1. Áreas significantes para o desenvolvimento da educação em enfermagem

2. Áreas alvo para a pesquisa em educação em enfermagem

3. Recomendações relativas a métodos de pesquisa e instrumentos

4. Avanço dos papéis da pesquisa, responsabilidades e posições

5. Políticas que devem ser perseguidas em níveis local, regional, nacional e internacional

6. Fundos

7. Estratégias recomendadas

\section{1. Áreas significantes para o desenvolvimento da educação em enfermagem}

Iniciamos identificando os problemas da educação em enfermagem onde há uma defasagem no conhecimento. O Comitê identificou uma lista de problemas que devem servir como um incentivo à pesquisa nesse campo. Áreas significantes para esse desenvolvimento incluem:

- Reconhecimento das contribuições da enfermagem para a sociedade, buscando recursos e apoio, especialmente através de fundos para a educação em enfermagem, básica, pós-básica e extensão.

- Acentuar a qualidade da educação em enfermagem, reconhecendo as diferenças entre os padrões de qualidade da educação em enfermagem no mundo.

- Desenvolvimento e teste de modelos inovadores de ensino em sala de aula e em campo; avaliação dos modelos atuais de pesquisa em relação à qualidade dos resultados e sua efetividade; aumentar a habilidade do quadro acadêmico e clínico.

- Fortalecimento das habilidades clínicas dos educadores e o ensino de um julgamento clínico. 
- Avaliação dos conceitos de enfermagem buscando a relevância curricular com atenção específica a aplicação da teoria na prática.

- Enfocar a preparação do professor, incluindo as competências clínicas, treinamento para pesquisa e comprometimento com o ensino como uma carreira.

- Definir as vantagens do sistema educacional de enfermagem e desenvolver novos modelos, incluindo aspectos organizacionais das Escolas de Enfermagem.

- Aumentar a consciência entre as enfermeiras educadoras da necessidade da pesquisa para a educação em enfermagem visando o aprimoramento do conhecimento sobre a disciplina; enfatizando o papel específico dos educadores no apoio a pesquisa sobre educação em enfermagem.

- Avaliação dos modelos atuais de desenvolvimento de currículos, incluindo atenção ao conteúdo essencial e prioridades para a satisfação legal dos requisitos e necessidades profissionais.

- Fortalecimento do relacionamento entre a educação e os serviços objetivando ao aumento da ligação entre a prática e a pesquisa. Educação visando sanar as necessidades futuras da sociedade.

- Avaliar os componentes da educação em enfermagem focalizando os objetivos de cuidado de saúde primários.

- Aumentar as áreas comuns entre a educação em enfermagem com a educação de outros profissionais da saúde, avaliando as mudanças na enfermagem e efeitos em outros profissionais da saúde.

- Avaliar o isolamento social de alguns estudantes de enfermagem em alguns programas em outros países e o valor de uma educação mais abrangente baseada na Universidade.

- Atingir as necessidades de extensão de enfermeiras profissionais.

- Desenvolver modelos de educação continuada-ensino e aprendizado.

\section{2. Áreas alvo para a Pesquisa em Educação em Enfermagem}

Refere-se aos problemas mais urgentes em uma perspectiva abrangente. As áreas identificadas como prioridades para pesquisa são as seguintes:

- Pré-requisitos para a admissão em programas de educação em enfermagem e seleção de procedimentos.

- Relação entre o nível de educação em enfermagem e os resultados para a saúde.

- Métodos de educação para o relacionamento interpessoal, uso de relações interpessoais, desenvolvimento de comunicação e habilidades de colaboração com pacientes/clientes, famílias e outros profissionais da saúde.

- Avaliação dos laboratórios e clínicas para a educação em enfermagem.

- Avaliação dos pontos em comum entre os métodos de ensino e o aprendizado dos alunos.

- Avaliação dos meios de ensino de valores, ética e influência no domínio 
afetivo.

- Critério para avaliar o aprendizado de diferentes habilidades.

- Métodos de assistência aos alunos de níveis mais avançados para que assimilem aspectos do papel do profissional, refletindo nos serviços, educação, pesquisa e administração.

- Avaliação dos modelos para educação geral e específica em enfermagem e seu impacto no papel do professor, avaliação dos efeitos do modelo de educação na prática de enfermagem.

- Necessidades de educação em enfermagem e modelos de educação para a preparação dos profissionais.

- Métodos de preparação de professores, incluindo o ensino da pesquisa em todos os níveis da educação em enfermagem.

- Métodos e ferramentas para a condução da pesquisa em educação em enfermagem, com atenção particular a suas dimensões internacionais.

- Experimentos como uso de diferentes formas de tecnologia de informação para aumentar a efetividade e eficiência da educação em enfermagem.

- Identificação de métodos para o avanço no uso das tecnologias de informação para apoiar as pesquisa de educação em enfermagem.

- Desenvolvimento de modelos de pesquisa em educação.

\section{Recomendações relativas aos métodos e instrumentos de pesquisa}

O desenvolvimento da enfermagem em todos os países do mundo está produzindo modelos de conhecimento com algumas características em comum; Entretanto, algumas inovações em potencial para a educação em enfermagem ainda permanecem em níveis locais, sem difusão para fora das fronteiras dos países. A dialética entre as diversidades culturais e costumes nacionais poderia ser uma importante tentativa para melhorar os níveis de educação em enfermagem na próxima década. Pesquisas em vários locais e culturas permitiram o aumento da generalização dos achados científicos e, ao mesmo tempo, reduziriam as diversidades nacionais. Desse modo, a transferência dos achados de pesquisa para a prática em diferentes lugares necessita ser melhor explorada. Colaboração multinacional em pesquisa em educação em enfermagem deveria ser uma das mais importantes metas para o futuro próximo.

O Comitê recomenda uma tentativa eclética para a pesquisa. Assim, uma grande variedade de métodos de pesquisa devem ser usados, de acordo com o fenômeno estudado. Ambos, métodos qualitativos e quantitativos são recomendados para se atingir a integração entre eles. Em alguns projetos de pesquisa complexos a "triangulação" pode ser usada. Referindo-se a alguns dos pontos citados como tendências, exemplos são dados para se salientar a importância de métodos diferentes. Para descrever modelos específicos de 
educação nacional e suas peculiaridades, a pesquisa histórica tem sido útil. Através desse estudo, pode-se descobrir circunstâncias e eventos passados que influenciaram a educação em enfermagem. Na busca do conhecimento, a história pode ser usada para predizer o futuro e, nessa perspectiva, estudos sobre antigos métodos de ensino de habilidades de enfermagem poderiam, talvez, revelar técnicas úteis que já foram esquecidas.

Em face de uma sociedade formada por múltiplas etnias, as escolas de enfermagem, em muitos países, deveriam conter essa diversidade na composição de estudantes e alunos. Pesquisas comparativas de diversas culturas, assim como etnográficas, deveriam ser incentivadas na busca de atitudes e valores culturais e seu impacto no processo educacional. Desse modo, esforços precisam ser envidados para o aumento de pesquisas relativas ao desenvolvimento e ao impacto dos atos didáticos em diferentes lugares e circunstâncias; métodos experimentais e quase-experimentais são os mais usados nestes casos. Finalmente, em projetos de pesquisa, atenção deve ser dada aos métodos, procurando-se entender seu potencial no campo da pesquisa em educação e, talvez, na procura de outros. A revisão crítica da literatura, incluindo metaanálise, deve crescer.

A meta da educação, incluindo a educação em enfermagem, é influenciar a mudança do comportamento humano em uma direção específica. No caso da educação em enfermagem, objetiva-se a congruência entre o comportamento do aprendiz e o comportamento esperado de uma pessoa que está prestando cuidados de enfermagem em uma determinada unidade de saúde. Partindo-se da idéia de que os resultados da educação influenciam o comportamento humano, os métodos usados para estudar o sistema de educação em enfermagem deverão ser baseados nos dados, refletindo o comportamento do aprendiz e do professor de enfermagem. Instrumentos para o estudo desses comportamentos, ambos verbal e não-verbal, podem ser agrupados em instrumentos de pesquisa interacional e instrumentos que utilizam técnicas não-verbais na coleta de dados. Instrumentos de pesquisa interacional são baseados na interação entre o pesquisador e os sujeitos, através da verbalização direta ou questionários, e, portanto, são considerados mais "intrusos" que as técnicas não-verbais de observação participativa ou não participativa, pesquisa histórica, etc. Várias técnicas não-verbais alternativas existem para a observação de fenômenos relevantes para a educação em enfermagem. Os instrumentos sugeridos não estão completamente relacionados e, assim, o pesquisador deve constantemente estar alerta para as possibilidades de desenvolver novos modos de coleta de dados, que melhor respondam as suas necessldades de pesquisa. Como exemplos de instrumentos usados, podem ser citados os questionários, observação, entrevistas, entrevistas diárias. Deve ser prestada particular atenção para a validade e forma dos instrumentos, pois eles são usados em diferentes grupos culturais. 


\section{Avanço dos papéis da pesquisa, responsabilidades e posições}

Mesmo que o desenvolvimento da educação seja uma obrigação ética de cada enfermeira, pessoas diretamente envolvidas neste campo investiram mais para este avanço. O docente e o pesquisador têm responsabilidades adicionais, além do desenvolvimento de seus projetos de pesquisa, como o ensino baseado na pesquisa e a expectativa de que os seus alunos reflitam a partir de uma prática baseada na pesquisa. Os educadores enfermeiros devem também promover a pesquisa em educação e estimular indivíduos e instituições a subvencioná-las.

Das organizações profissionais, espera-se que invistam neste tipo específico de pesquisa, pois o investimento no futuro da educação constitui o caminho principal para o aperfeiçoamento dos serviços de enfermagem e, conseqüentemente, para a melhora do status da profissão diante da sociedade com o reconhecimento da contribuição dos enfermeiros para a saúde.

Os ambientes mais apropriados para a promoção, organização e administração de pesquisas em educação são as Universidades e os institutos de pesquisa. Eles podem fornecer habilidade metodológica e recursos técnicos apropriados para serem usados nos projetos. Adicionalmente, eles têm uma visão mais ampla e podem desenvolver redes de projetos de pesquisa.

Lugares para o desenvolvimento de pesquisa incluem todos os tradicionais institutos de ensino, assim como, por exemplo: salas de aula, laboratórios, clínicas, casa dos pacientes e serviços na comunidade.

\section{Políticas que devem ser perseguidas em níveis local, regional, nacional e internacional}

Visando o aumento da atenção dispensada ao assunto propõe-se que as recomendações sejam disseminadas em múltiplos níveis e entre vários grupos.

Educadores de enfermagem envolvidos com a pesquisa podem assumir a responsabilidade para aumentar o nível de conhecimento a respeito de políticas específicas. Ações individuais são solicitadas, mas não são suficientes. A níveis local, regional, nacional e internacional, políticas formais devem ser promovidas. Instituições devem ser encorajadas para escrever sobre o assunto, como:

- Resoluções de Organizações Profissionais (Associações Nacionais).

- Manifestações de apoio, ex. OMS, Conselho da União Européia e outras organizações internacionais ligadas a saúde.

- Nações, através da elaboração de políticas.

\section{Fundos}

Opções de formas de subvenção devem ser exploradas, incluindo aquelas que ainda não foram solicitadas. É de fundamental importância que as 
enfermeiras educadoras determinem relações específicas e diretas entre a pesquisa e as metas das agenclas financiadoras em potencial e que, ao mesmo tempo, influenciem as prioridades destas agências.

Exemplos de fontes de suporte em potencial:

- Ministério, Departamentos/ organizações internacionais e nacionais, associações de enfermagem.

- Empresas multinacionais, especialmente aquelas com interesse na área da saúde.

- Fundações.

\section{Estratégias recomendadas}

Esforços devem ser enviados para identificar e iniciar múltiplas estratégias.

Exemplos de estratégias:

- Campanhas de informação pública divulgando os achados de pesquisa, dentro e fora do campo profissional.

-Criação de um sistema de informações que permita que os progressos sejam compartilhados.

- Uso de computadores e outros tipos de tecnologia no desenvolvimento da pesquisa e na sua divulgação.

- Desenvolvimento e/ou expansão de um sistema que possibilite a recuperação que inclua a classificação em enfermagem.

- Disseminação da informação relativa às metodologias de pesquisa e aos seus achados.

- Conferências e outros métodos para se compartilhar informações e trocar idéias e experiências relevantes para a educação em enfermagem.

- Aumento do intercâmbio de pesquisas através de revistas internacionais de enfermagem.

- Submeter a apreciação das agências financiadoras propostas que envolvem vários países.

- Fortalecer os componentes de pesquisa dos currículos em todos os níveis.

- Introduzir pesquisa sobre o currículo dos professores visando preparar uma massa crítica de educadores em enfermagem que estão preparados para ensinar a partir de uma base de pesquisa e conduzi-la nessa direção; desenvolver programas de educação continuada em pesquisa para os professores.

- Introduzir seções de pesquisa em educação em enfermagem durante as conferências de pesquisas.

\section{CONCLUSÃO}

Esse documento enfatiza uma estrutura de pesquisa em educação que deve ser seguida no futuro; só será efetiva, se as enfermeiras se prontificarem a 
resolver os problemas citados e desenvolverem projetos de pesquisa. Muitas estratégias foram identificadas; agora está a cargo de cada uma das enfermeiras, pesquisadoras, professoras, executivas, diretoras de escolas de enfermagem, colocarem em prática essas estratégias. Serão muitos os obstáculos até a obtenção desses objetivos. O contexto global caracteriza-se por sua complexidade; economias nacionais são desafiadas em um momento em que a demanda cresce e a prestação de serviços de saúde se modifica. O papel da enfermeira deve ser fortalecido, assim como a enfermagem na prestação de cuidados de saúde, particularmente em relação aos cuidados primários de saúde e os cuidados domiciliares. A educação é o instrumento mais importante, entretanto, o seu desenvolvimento está largamente ligado à pesquisa. Assim sendo, deve-se aumentar o número de projetos de pesquisa.

No futuro vislumbram-se perspectivas de globalização e, nesse contexto, projetos de pesquisa devem ser desenvolvidos local e internacionalmente. A cooperação internacional pode valorizar experiências individuais e enriquecer o conhecimento comum. É importante ressaltar que: o trabalho conjunto requer habilidades específicas, o que inclui o entendimento da diversidade cultural, o aprendizado com cada tentativa e experiência e o desenvolvimento de uma atitude voltada para o "APRENDER". Esse é o grande desafio. Através da pesquisa em educação, a enfermagem no mundo pode mudar e todos podem contribuir com essa mudança.

Pessoas que participaram da Conferência de Bolzano, Itália, vieram de 36 países. Esse documento contém muitas das suas sugestões. A esperança é de que essas sugestões se espalhem para outros países e pessoas, incentivando-os a iniciar uma rede de cooperação em pesquisa que englobe todo o mundo. 